University of Nebraska - Lincoln

DigitalCommons@University of Nebraska - Lincoln

Faculty Publications from the Department of Electrical \& Computer Engineering, Department Electrical and Computer Engineering

1999

\title{
Doppler Measurements Using a Coherent Ultrawideband Random Noise Radar
}

\author{
Muhammad Dawood \\ University of Nebraska-Lincoln \\ Ram M. Narayanan \\ University of Nebraska-Lincoln
}

Follow this and additional works at: https://digitalcommons.unl.edu/electricalengineeringfacpub

Part of the Electrical and Computer Engineering Commons

Dawood, Muhammad and Narayanan, Ram M., "Doppler Measurements Using a Coherent Ultrawideband Random Noise Radar" (1999). Faculty Publications from the Department of Electrical and Computer Engineering. 144.

https://digitalcommons.unl.edu/electricalengineeringfacpub/144

This Article is brought to you for free and open access by the Electrical \& Computer Engineering, Department of at DigitalCommons@University of Nebraska - Lincoln. It has been accepted for inclusion in Faculty Publications from the Department of Electrical and Computer Engineering by an authorized administrator of DigitalCommons@University of Nebraska - Lincoln. 


\title{
Doppler Measurements Using a Coherent Ultrawideband Random Noise Radar
}

\author{
Muhammad Dawood* and Ram M. Narayanan \\ Department of Electrical Engineering and Center for Electro-Optics \\ University of Nebraska, Lincoln, NE 68588-0511 \\ Tel: 402-472-5141, Fax: 402-472-4732, Email: rnarayanan@unl.edu
}

\section{Introduction}

The University of Nebraska has developed a random noise radar system which transmits an ultrawideband random noise waveform with a uniform power spectral density (PSD) in the 1-2 GHz frequency range. Simulation studies and controlled laboratory tests confirm the system's ability to preserve the instantaneous phase of the received signal $[1,2]$. The potential of the system to characterize the Doppler shift of moving targets exhibiting varying linear and rotational velocities was clearly demonstrated [2].

This paper provides with the results of recent field experiments at a range of about $200 \mathrm{~m}$ which confirm the ability of the system to be used as a Doppler radar in operational scenarios.

\section{Radar System Description}

A simplified block diagram of the random noise Doppler radar is shown in Fig. 1. The noise source $\mathrm{OSCl}$ produces a signal with a Gaussian amplitude distribution, constant PSD, and average output level of $0 \mathrm{dBm}(1 \mathrm{~mW})$ in the 1-2 GHz frequency range. The noise source output is split into two equal in-phase components in power divider PD1. A 10 Watts transmit power is achieved through a TWT broadband amplifier AMP1 and transmitted via a horn antenna ANT1. The second output of PD1 is connected to a combination of a fiber optic (FO) fixed delay line DL1 and a digitally controlled variable delay line DL2. The fixed delay line provides $1.5 \mu \mathrm{sec}$ delay, while the variable delay line can be programmed for delays from 0 to $19.968 \mathrm{~ns}$ in $0.156 \mathrm{~ns}$ steps. The delay line output is mixed with the output of a $160 \mathrm{MHz}$ phase-locked oscillator OSC2 in a lower sideband upconverter MXR1, whose outputs feed each receive chain via PD3.

A 1-2 GHz signal received by antenna ANT2 provides the second input to mixer MXR2. the mixing operation. The $160 \mathrm{MHz}$ output of MXR2 is filtered in a $160 \mathrm{MHz}$ bandpass filter FL1 and split in power divider PD5. One of the outputs of PD5 is amplified in logarithmic amplifier AMP7 to yield the signal amplitude, and the other output is fed to I/Q detector IQD1 to yield the in-phase (I) and quadrature (Q) components of the received signal. A similar receiver is used for the second receive chain connected to antenna ANT3. The E/H plane beamwidtis and gain of all antennas at $1.5 \mathrm{GHz}$ are $23^{\circ}, 34^{\circ}$, and $17 \mathrm{~dB}$ respectively.

\section{Theoretical Considerations}

The transmit waveform of the system can be modeled as $[1,2]$ :

$$
v_{t}(t)=a(t) \cos \left\{2 \pi\left(f_{0} \pm \delta f\right) t+\psi_{t}\right\}
$$

where $a(t)$ represents the Gaussian amplitude distribution, $f_{0}$ is the center frequency at 1.5 $\mathrm{GHz}, \delta f$ is uniformly distributed over the $\pm 0.5 \mathrm{GHz}$ frequency range, and $\psi_{t}$ is the arbitrary transmitter phase.

If the target is in motion, the in-phase $I$ and quadrature $Q$ components of the received waveform can be shown to be [2]:

$$
I=k_{I} \cos \left\{-\frac{4 \pi V}{\lambda} t+\psi_{s}\right\}
$$




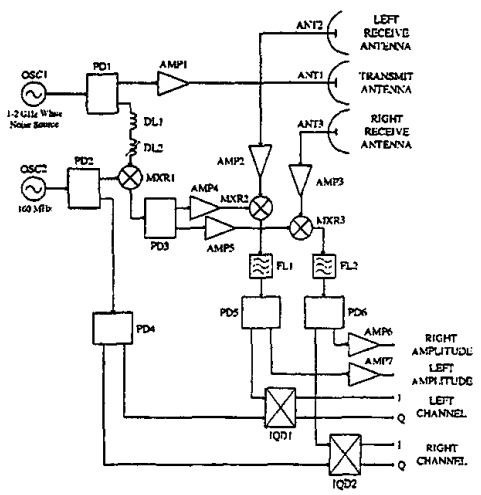

Figure 1: Block diagram of coherent ultrawideband random noise radar.

$$
Q=k_{Q} \sin \left\{-\frac{4 \pi V}{\lambda} t+\psi_{s}\right\}
$$

where $k_{I}$ and $k_{Q}$ represent the amplitudes of the $I$ and $Q$ components respectively, and the instantaneous wavelength $\lambda=c /\left(f_{0} \pm \delta f\right)$. Note that Doppler frequency is not constant, but varies due to the varying nature of the instantaneous wavelength $\lambda$.

\section{Experimental Setup}

A large corner reflector with $45.7 \mathrm{~cm}$ sides with a radar crossection (RCS) value of $6.6 \mathrm{dBsm}$ at $1.5 \mathrm{GHz}$ mean frequency was chosen as the target. Since each radar range bin is $15 \mathrm{~cm}$ long, a linear array of such corner reflectors was mounted at a height of 3 meter atop a van.

The radar system was mounted inside another van, and the antennas were mounted on top of the 10-m high telescopic boom. The distance between the stationary radar van and the moving target van was approximately $200 \mathrm{~m}$. The overall geometry of these experiments is shown in Figure 2.

\section{Experimental Results}

The target van approached the radar van along the boresight direction with approximate uniform velocities of $4.5 \mathrm{~m} / \mathrm{sec}$ and $9 \mathrm{~m} / \mathrm{sec}$ with corresponding mean Doppler frequencies of $45 \mathrm{~Hz}$ and $90 \mathrm{~Hz}$, respectively. Each experiment was also repeated at $1.5 \mathrm{GHz}$ fixed frequency, and using 1.4-1.6 GHz random frequency. At each speed, ten trials were carried out and final results are depicted in Figures 3 and 4 . These figures show the individual trials along with the extracted mean Doppler. The solid line is the averaged Doppler from ten individual trials (dotted).

It can be seen that:

(1) the Doppler frequency associated with a moving target can be extracted using the UWB random noise system developed by UNL,

(2) the estimated Doppler using comparatively narrow bandwidth (i.e. $200 \mathrm{MHz}$ ) is almost identical to that using fixed frequency, and

(3) the Doppler spread increases at higher bandwidths and higher target velocities. 


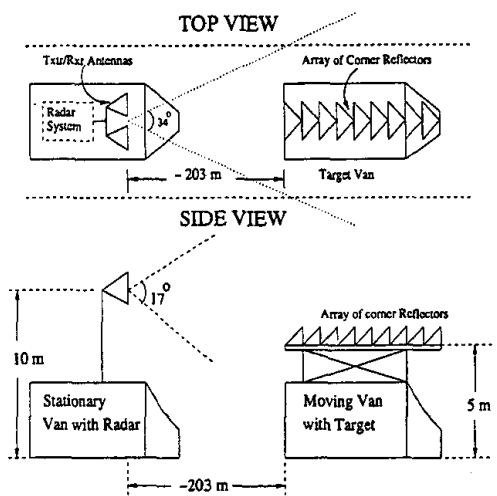

Figure 2: Geometry of field experiments for Doppler measurements.

\section{Conclusions}

The experiments demonstrate the potential of random noise radar to be used as a Doppler radar. The radar's unique concept synergistically combines the advantages of random noise transmission with the power of coherent signal processing to yield a powerful technique for velocity tracking and scanning applications. The advantages of random noise radar, such as its small size, low power and immunity from interference, make it a promising candidate for civilian and military applications.

\section{Acknowledgments}

This work was supported by Office of Naval Research(ONR) contract \# N00014-97-1-0200. We appreciate the helpful comments provided by Dr. William Miceli of ONR. We acknowledge the help and cooperation extended by Dr. Steve Pappert of SPAWAR for providing us with the fiber optic delay line system. We also acknowledge the assistance of Doug Kramer, Dmitriy Garmatyuk, Daryl Bell, Evgueni Borissov and other members of Environmental Remote Sensing Lab (ERSL) of UNL during the field measurements.

\section{References}

[1] R. M. Narayanan, R. D. Mueller and R. D. Palmer, "Random noise radar interferometry", Proc. SPIE Conference on Radar Processing, Technology, and Applications, (W. Miceli, Ed.), Volume 2845, pp. 75-82, August 1996.

[2] R. M. Narayanan, M. Dawood, R. D. Mueller and R. D. Palmer, "Doppler estimation using a coherent ultrawideband random noise radar", Proc. SPIE Conference on Radar Processing, Technology, and Applications II, (W. Miceli, Ed.), Volume 3161, pp. 70-76, August 1997. 


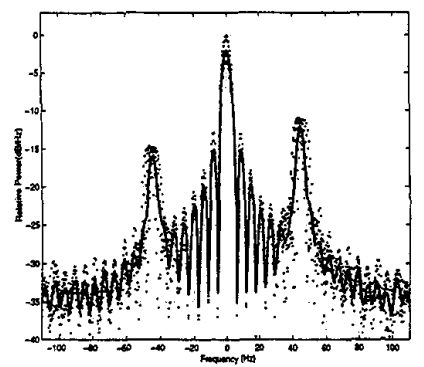

(a) Transmit Frequency 1.5 GHz (fixed)

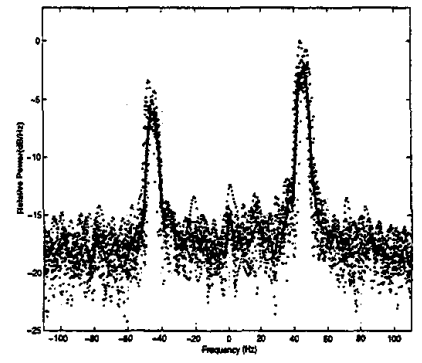

(b) Transmit Frequency 1.4-1.6 GHz (random)

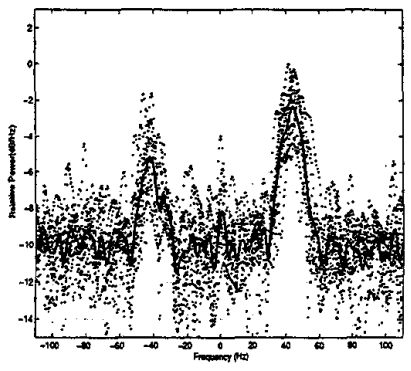

(c) Transmit Frequency 1-2 GHz (random)

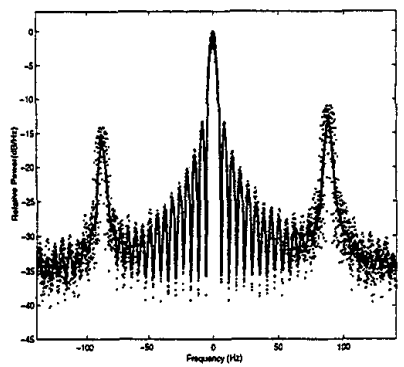

(a) Transmit Frequency $1.5 \mathrm{GHz}$ (fixed)

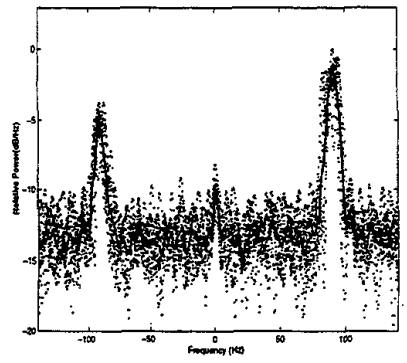

(b) Transmit Frequency 1.4-1.6 GHz (random)

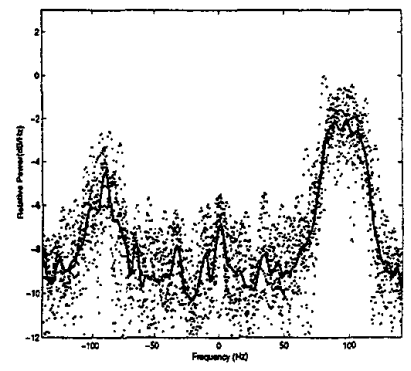

(c) Transmit Frequency 1-2 GHz (random)

Figure 3: Doppler spectra of target moving at $4.5 \mathrm{~m} / \mathrm{sec}$

Figure 4: Doppler spectra of target moving at $9 \mathrm{~m} / \mathrm{sec}$ 